\title{
Impact of the Covid-19 lockdown on sexual assault cases in Eastern Denmark - a retrospective clinical forensic study
}

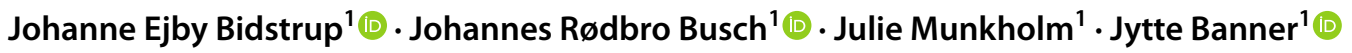

Accepted: 15 December 2021 / Published online: 29 January 2022

(c) The Author(s), under exclusive licence to Springer Science+Business Media, LLC, part of Springer Nature 2021

\begin{abstract}
To explore if the shutdown of Danish nightlife during the Covid-19 pandemic caused a decrease in the number of clinical forensic examinations of victims of sexual assault in Eastern Denmark. Secondarily, to investigate, if there was a change in criminological characteristics, e.g. scene and time of crime, relation to the perpetrator and the proportion of possible drugfacilitated sexual assaults. 130 case files from clinical forensic examinations of individuals of alleged sexual assault in the period $1^{\text {st }}$ of April to 30 $0^{\text {th }}$ of June in both 2019 and 2020 were included. 67 and 63 examinations were performed in 2019 and 2020, respectively. 125 cases were female and five were male. Approximately $70 \%$ were $15-25$ years of age. Pre- and postlockdown victim profiles were similar regarding assailant relation, location of crime and time of assault. Voluntary intake of alcohol prior to the assault was registered with $46.3 \%$ in 2019 and $62 \%$ in 2020 . The ratio of possible drug-facilitated sexual assault (DFSA) was approximately 50\% each year. The lockdown did not seem to change the overall number of examinations or the demographic and criminological characteristics of the sexual assault victims. No decrease in cases of possible DFSA was found despite the lockdown of nightlife venues.
\end{abstract}

Keywords Clinical forensic medicine $\cdot$ Sexual assault $\cdot$ Epidemiology $\cdot$ Covid-19 $\cdot$ Drug-facilitated sexual assault

\section{Introduction}

Sexual assault continues to be a great public health concern around the world [1]. It is estimated that the yearly number of attempted or completed sexual assaults in Denmark is around 5400 cases, with only about $1 / 6$ of the cases reported to the police $[2,3]$. Studies show that sexual assault is a crime biased towards women, in that more than $90 \%$ of the victims are female [4-9]. A significant amount of underreporting is suspected due to several reasons, e.g. guilt,

Johanne Ejby Bidstrup

Johanne@ejbybidstrup.dk

Johannes Rødbro Busch

johannes.busch@sund.ku.dk

Julie Munkholm

julie.munkholm@sund.ku.dk

Jytte Banner

jytte.banner@sund.ku.dk

1 Department of Forensic Medicine, Section of Forensic Pathology, University of Copenhagen, Frederik V's Vej 11, 2100 København Ø, Denmark shame, partial or complete amnesia as well as pre-existing relations with the perpetrator $[3,10,11]$.

A strong relation between sexual assault and the intake of alcohol and drugs has been seen in previous studies [7, $8,12-17]$. On the $11^{\text {th }}$ of March 2020, Danish society was partially shut down due to the Covid-19 pandemic, resulting in mandatory closure of restaurants, bars and clubs, and restrictions on size of social gatherings. During the following months, the society was gradually reopened. The yearly report published by the Centre for Sexual Assaults in Copenhagen (In Danish "Center for Seksuelle Overgreb", or CSO) [5] showed that more assaults happened in private homes in 2020 compared to 2019 as well as an increase in the number of cases with contact established through the internet, e.g. online dating apps or other social media [5, 18]. However, it is not known if the lockdown of society caused a decrease in the number of forensic clinical examinations of victims, or if it caused a change in the type of sexual assault crimes committed.

Thus, the aim of this study was to explore if the shutdown of Danish nightlife during the Covid-19 pandemic caused a decrease in the number of clinical forensic examinations of victims of sexual assault in Eastern Denmark. The secondary 
aims were to investigate if there was a change in criminological characteristics, e.g. scene and time of crime, relation to the perpetrator, as well as a change in the proportion of possible drug-facilitated sexual assaults.

\section{Background}

\section{Definition and categorization of sexual assault}

According to the Danish Criminal Code the only clearly defined type of sexual assault crime is rape. The following definitions, excluding that of rape, are therefore not as stated in the Danish Criminal Code, but based on definitions regularly used in the scientific literature.

Sexual assault is defined as an unwanted or forced sexual activity of any kind, with or without physical contact $[6,7]$.

Rape is defined as coitus without consent [14, 19]. Based on the relation between victim and assailant, rape is typically further subcategorized as stranger-, contact- and partner rape [2].

Drug-facilitated sexual assault (DFSA) is defined as sexual assault with absent or invalid victim consent due to the influence of alcohol and/or drugs [7, 12, 20]. If the assault involves intercourse, it is sometimes referred to as drug-rape [14]. There are two primary types of DFSA [7, 12]: Proactive DFSA refers to the perpetrator's active administration of a substance with psychoactive properties, incapacitating the victim for the purpose of facilitating a non-consensual sexual act. In opportunistic DFSA an individual is incapable of consenting to a sexual activity due to voluntary intake of substances with psychoactive properties. The perpetrator does not actively contribute to the intoxication but takes advantage of the victims' incapacitation in consenting to sexual activity $[7,12,20]$. Though there has been a lot of focus on the so called "date-rape drugs", e.g. drugs used to incapacitate the victim but not necessarily administered by a date $[7,8,21,22]$, the most widespread substance in relation to DFSA is alcohol [12-16, 23, 24].

\section{Categorization of factors associated with sexual assault}

The great variation in categorization of factors associated with sexual assault in previous studies makes inter-study comparison difficult. In the following, we provide a brief overview of operationalization used by previous studies, to better enable comparison with our own definitions, as described in the Methods section.

\section{Assailant relation}

Studies have shown that most assaults happen in private homes and that the assailant usually is someone familiar to the victim (e.g. a friend, date or ex-boyfriend) $[2,9,14,16$, $23,24]$. The categorization of the assailant relation varies greatly from study to study and many different definitions are used in the literature. Some studies differentiate between previous and current partners [14, 23] while other studies merge them into one category [7, 15, 24]. The category "romantic relation" is also used and includes everything from a steady partner to a first date $[15,24]$. The category "acquaintance" is sometimes divided into "recent acquaintance" (met same day) and "casual acquaintance" (had met previously) $[7,14,23]$. Some studies further include "friend" into the category of acquaintance [24] though other studies treat it as an individual category [14-16, 23]. Categories such as "neighbor", "co-worker" and "client" are used by previous studies as well $[7,14]$. Most studies include the category "others", "unknown assailant" and"stranger", though it is highly inconsistent what the categories include, and the specific definitions may vary according to the other categories defined by the given study.

\section{Location of crime}

Common categories for the location of crime consist of the following: "own house", "assailant's house", "friend/other known person's house", "open space/outdoor locations", "public venues/bars", "other" and "unknown" [9, 16, 23]. Some studies further include the categories "vehicle/motor car" and "hotel/motel room" [15, 16, 23].

\section{Time of assault}

Regarding the association between sexual assault and alcohol, which is most commonly consumed in the late hours and during the weekend, studies have shown that most sexual assaults happen in the early morning (e.g. 12 p.m. -6 a.m.) [16] and that there might be a connection between day of the week (weekend vs. weekday) and sexual assault [4, 8]. Because data usually depend on testimony from victims and witnesses, the specific time of the crime is usually unknown, and therefore broad time slots, e.g. "early morning (12 p.m. -6 a.m.)" are used.

\section{Materials and methods}

\section{Setting}

This study was based on data from The Department of Forensic Medicine, University of Copenhagen. The study 
included all adolescent and adult complainants ( $\geq 15$ years) examined from $1^{\text {st }}$ of April to $30^{\text {th }}$ of June in both 2019 and 2020 , for a total of 130 cases. 125 victims were female and 5 were male.

For this study, victims of all types of sexual assault were included. All examinees provided a blood and urine sample which was kept in custody at our department, although the police requested a toxicological examination in only 12 out of 130 cases, 7 (10\%) and 5 (8\%) in 2019 and 2020, respectively.

All clinical forensic examinations conducted at the department follow an accredited procedure (ISO 17020) to ensure homogeneity in recorded information and objective findings [25].

\section{Data collection and registration}

Based on data from the written clinical forensic examination reports, a project database was created (see Table 1). The forensic case files included a systematic forensic medical history, registration of the circumstances of the assault, complainant data, objective findings including evidence of sustained injuries, and the type of forensic evidence collected. The examination reports build on statements from the police, the complainant and observations from the clinical forensic examination, as well as the forensic medical examiner's assessment of these data.

Every case was registered with a case file number, as well as demographic and assault characteristics (see Table 1). All examinations were performed by the Department of Forensic Medicine in Copenhagen.

All parameters in the database were defined before data collection was commenced to ensure continuity in the registration and unambiguous interpretation of the data sources.

Table 1 Database registrations

\begin{tabular}{l}
\hline Case file number \\
Reported to the police (yes/no) \\
Sex (male/female) \\
Victim's age (years) \\
Region of requested \\
examination (based on police \\
precincts) \\
Year and month of assault \\
Date of examination \\
Date of assault \\
Date of assault \\
Weekday of assault \\
Time of assault \\
Assailant relation \\
Location of crime \\
Possible DFSA \\
\hline
\end{tabular}

In line with previous studies, a case was registered as possible DFSA, if one or more of the following criteria were met:

1. The victim reported coerced consumption of alcohol and/or drugs prior to the assault.

2. Any suspicion of drink spiking the victim may have had.

3. If the victim appeared possibly intoxicated by drugs and/ or alcohol at the clinical examination.

4. If the victim exhibited partial or complete amnesia for the assault.

Suspicion of a spiked drink was considered positive if an abnormal reaction after a drink (alcoholic/non-alcoholic) was reported, as judged by the victim. In addition, voluntary intake of drugs or alcohol prior to the assault was registered but not considered enough in itself to classify the case as suspicion of spiked drink.

Possible intoxication from drugs or alcohol at the clinical examination was considered positive if one of the following was registered: 1) Smell of alcohol, 2) Impaired balance, 3) Slurred speech, 4) Unsuccessful finger-nose test, 5) Miosis/mydriasis.

The degree of amnesia for the assault was classified as: 1) No amnesia for the assault, 2) Partial amnesia for the assault, 3) Complete amnesia for the assault. Complete amnesia for the assault was considered positive if the victim had a feeling of an occurred sexual assault (e.g. lower abdominal pain, vaginal soreness) or if someone familiar to the victim could confirm the incidence.

For the purpose of this study the assailant relation was registered as partner (a person to whom the victim previously or currently had a sexual relation), close relation (family, friends), date (acquaintances, persons to whom the victim had a romantic or potential sexual relation), stranger (a person unknown to the victim), other (e.g., a teacher, a boss), or unknown (used in cases with complete amnesia for the assault and thereby no report of assailant relation). Due to a low number of observed cases in some categories, four victim-assailant relation categories were ultimately defined, through merging of some subcategories: Partner (current + previous), known relation (date + close relation + other), stranger (stranger) and unknown.

In the present study, location of crime was registered as own house, friend's home, assailant's home, open space, club/ bar, other (e.g. a car, a public but not open space) or unknown (used in cases where no location of crime was registered in the reports). Day of assault was categorized as either weekdays (Monday to Thursday) or weekend (Friday to Sunday). Time of assault was registered in time periods of $6 \mathrm{~h}$ duration, starting at 12 a.m., 6 a.m., 12 p.m. and 6 p.m., respectively. Assaults with a duration overlapping categories (e.g., both 
"Sunday through Monday" or "11 p.m. to 1 a.m.") were registered in all involved categories.

\section{Statistical analyses}

The statistical analyses were performed in RStudio v. 1.4.1106 (C RStudio PBC, Boston, MA, USA) using the $\mathrm{X}^{2}$-test for unpaired, categorical data, Fisher's exact test for unpaired categorical data with less than 5 expected observations in at least one category, as well as the CochraneArmitage test for trend in binomial data over sequential ordinal categories. The Cochrane-Armitage test for trend was specifically used to explore whether there was a difference in time trend in frequency of examinations over the three months in 2019 compared to 2020. Differences were considered statistically significant at the 0.05 level.

\section{Ethical considerations}

This study is based on pseudo-anonymized registry data. All analyses and results are shown in an aggregated form so that three or less observations are registered as $\leq 3$. Data has been managed according to the European GDPR regulations.

\section{Results}

\section{Number of examinations}

67 and 63 examinations were performed in 2019 and 2020, respectively, the difference being statistically non-significant. In 2019 the distribution of examinations through the period of interest was roughly the same each month, with 20 (29.9\%) performed in April, 26 (38.8\%) in May and 21 (31.3\%) in June. In 2020 the number of examinations clearly increased through the months with 9 (14.3\%) performed in April, 24 (38.1\%) in May and 30 (47.6\%) in June (see Fig. 1).

We found a significant difference in the trend for number of cases per month in 2019 compared to $2020(\mathrm{p}=0.0179)$.

\section{Demography: (see Table 2)}

No significant difference between 2019 and 2020 was found regarding the victims' age or sex. Overall, about $70 \%$ of the victims were between $15-25$ years of age.

\section{Criminological profile: (see Table 3)}

\section{Assailant relation}

Overall, we found statistically significant differences in the distribution of assailant relation when comparing 2019 and

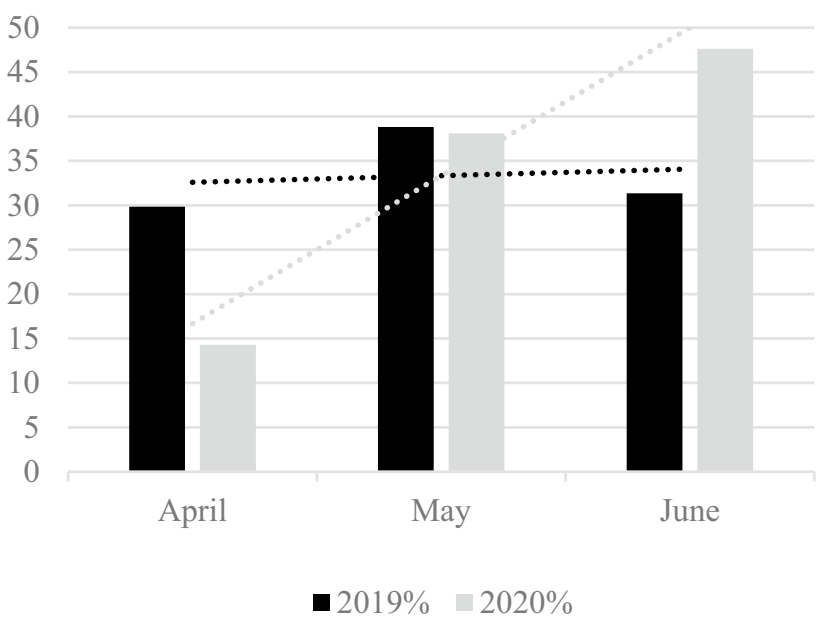

Fig. 1 Examinations per month. $\mathrm{n}=130 ; 67$ examinations in 2019, 63 examinations in 2020

$2020(p=0.0053)$. Significantly more cases of sexual assault by a stranger was reported in 2019 than 2020 (20.9\% and $12.7 \%$, respectively), which was also the case for unknown assailants $(13.4 \%$ vs. $<4.5 \%)$. There were significantly fewer cases of sexual assault by a partner in 2019 (<4.5\% vs. 6.9\%, respectively). Overall, by far the most commonly registered assailant relation was "known relation" with $64.2 \%$ of the cases in 2019 and $69.8 \%$ of the cases in 2020 .

\section{Location of crime}

We found no statistically significant difference in the recorded scene of the crime before and during the lockdown $(\mathrm{p}=0.1278)$. The most frequently registered location of crime was "assailant's house" with around 30\% in both 2019 and 2020, followed by "open space" in 2019 and "own house" in 2020 with around $20 \%$ of the cases in both years.

Table 2 Sociodemographic characteristics $(n=130)$

\begin{tabular}{llcll}
\hline & $n 2019$ & $\%$ & $n 2020$ & $\%$ \\
\hline $\begin{array}{llll}\text { Sex } \\
\text { Female }\end{array}$ & 63 & 94,0 & 62 & 98,4 \\
$\quad$ Male & 4 & 6,0 & $\leq 3$ & $\leq 4,5$ \\
Victim age & & & & \\
$15-19$ & 25 & 37,3 & 30 & 47,6 \\
$20-24$ & 20 & 29,9 & 13 & 20,6 \\
$25-29$ & 8 & 11,9 & 8 & 12,7 \\
$30-34$ & 5 & 7,5 & 5 & 7,9 \\
$35-39$ & $\leq 3$ & $\leq 4,5$ & $\leq 3$ & $\leq 4,5$ \\
$40-44$ & 4 & 6,0 & $\leq 3$ & $\leq 4,5$ \\
$>45$ & $\leq 3$ & $\leq 4,5$ & $\leq 3$ & $\leq 4,5$ \\
\hline
\end{tabular}


Table 3 Assault characteristics

\begin{tabular}{llllr}
\hline & $n 2019$ & $\%$ & $n 2020$ & $\%$ \\
\hline Assailant relation & & & & \\
Partner* & $\leq 3$ & $\leq 4,5$ & 9 & 6,9 \\
Known relation & 43 & 64,2 & 44 & 69,8 \\
Stranger* & 14 & 20,9 & 8 & 12,7 \\
Unknown* & 9 & 13,4 & $\leq 3$ & $\leq 4,5$ \\
Location of crime & & & & \\
Own House & 14 & 20,9 & 14 & 22,2 \\
Assailant's home & 19 & 28,4 & 20 & 31,7 \\
Friend's home & 6 & 9,0 & 12 & 19,0 \\
Open space & 16 & 23,9 & 13 & 20,6 \\
Club/bar & 4 & 6,0 & 0 & 0,0 \\
Unknown & $\leq 3$ & $\leq 4,5$ & $\leq 3$ & $\leq 4,5$ \\
Other & 6 & 9,0 & $\leq 3$ & $\leq 4,5$ \\
Day of assault & & & & \\
Mon-Thurs & 21 & 31,3 & 27 & 42,9 \\
Fri-Sun & 43 & 64,2 & 34 & 54,0 \\
Unknown & $<3$ & $<4,5$ & $<3$ & $<4,5$ \\
\hline
\end{tabular}

e.g., a car, public but not open space etc. *p 0.05
Though the difference was not statistically significant, we noted that no assaults were registered as having occurred in a "club/bar" in 2020 as opposed to four cases in 2019.

\section{Time and day of assault}

No significant difference was found in "time of assault" $(p=0.876)$ or "day of assault" $(p=0.25)$ when comparing 2019 and 2020. Most assaults happened during the weekend with $64.2 \%$ registered in 2019 and $54 \%$ in 2020 , and between 24 p.m. and 6 a.m. with $47 \%$ registered in this time period in 2019 and $54 \%$ in 2020.

\section{Drug-facilitated sexual assault: (see Table 4)}

According to our standardized definition, $47.8 \%$ of cases registered in 2019 compared to $44.4 \%$ in 2020 were possible DFSA $(\mathrm{p}=0.587)$.

Looking at individual DFSA-associated factors, complete amnesia for the assault was seen in $23.9 \%$ of the cases in

Table 4 Possible DFSA $(n=60)$

\begin{tabular}{|c|c|c|c|c|}
\hline & $n 2019$ & $\%$ & $n 2020$ & $\%$ \\
\hline \multicolumn{5}{|l|}{ Possible DFSA ${ }^{\mathrm{a}}$} \\
\hline Total & 32 & 47,8 & 28 & 44,4 \\
\hline April & 7 & 21,9 & 5 & 17,9 \\
\hline May & 15 & 46,9 & 9 & 32,1 \\
\hline June & 10 & 31,3 & 14 & 50,0 \\
\hline \multicolumn{5}{|l|}{ Suspicion of spiked drink } \\
\hline Yes & 14 & 20,9 & 12 & 19,0 \\
\hline No & 53 & 79,1 & 51 & 81,0 \\
\hline \multicolumn{5}{|c|}{ Appears affected by drugs/alcohol at the examination } \\
\hline Yes & 10 & 14,9 & 8 & 12,7 \\
\hline No & 57 & 85,1 & 55 & 87,3 \\
\hline \multicolumn{5}{|l|}{ Recollection of the assault } \\
\hline No amnesia for the assault & 38 & 56,7 & 44 & 69,8 \\
\hline Partly amnesia for the assault & 13 & 19,4 & 14 & 22,2 \\
\hline Complete amnesia for the assault* & 16 & 23,9 & 5 & 7,9 \\
\hline \multicolumn{5}{|c|}{ Partial/complete amnesia for the assault pr. month } \\
\hline April & 7 & 10,4 & $\leq 3$ & $\leq 4,5$ \\
\hline May & 12 & 17,9 & 7 & 11,1 \\
\hline June & 10 & 14,9 & 10 & 15,9 \\
\hline \multicolumn{5}{|c|}{ Voluntary intake of drugs/alcohol (up to $24 \mathrm{~h}$ prior to assault) } \\
\hline Alcohol & 31 & 46,3 & 39 & 61,9 \\
\hline Drugs & $\leq 3$ & $\leq 4,5$ & $\leq 3$ & $\leq 4,5$ \\
\hline Both & 8 & 11,9 & 11 & 17,5 \\
\hline No & 25 & 37,3 & 11 & 17,5 \\
\hline
\end{tabular}

a including suspicion of spiked drink, appears affected by drugs/alcohol at examination and amnesia for the assault (both partial and complete amnesia)

*p 0.05 


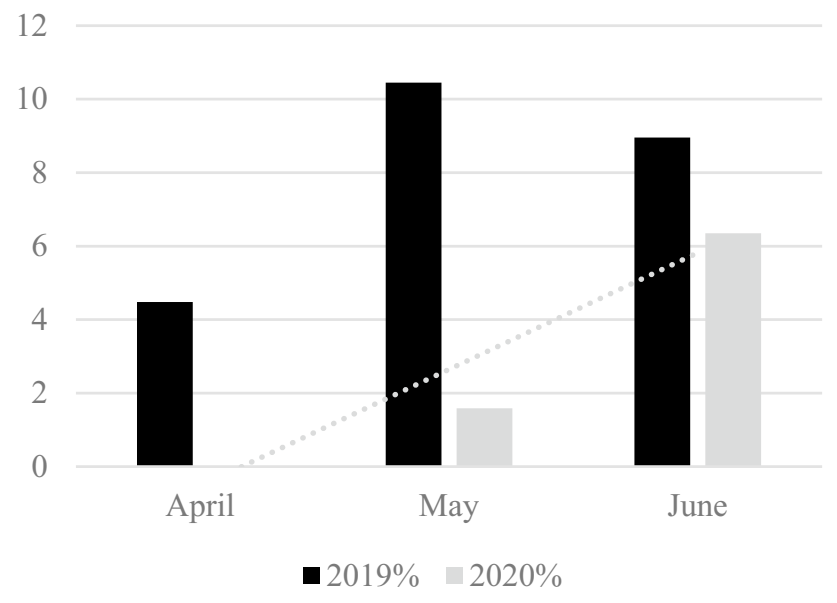

Fig. 2 Complete amnesia for the assault. $n=130 ; 67$ examinations in 2019,63 examinations in 2020

2019 and $7.9 \%$ of the cases in 2020 (see Fig. $2 ; p=0.03745$ ). No significant difference was found in partial/no amnesia for the assault, suspicion of spiked drink or clinical signs of drug/alcohol intoxication at the examination.

In 2019, 46.3\% reported a voluntary intake of alcohol up to $24 \mathrm{~h}$ prior to the assault compared to $62 \%$ in 2020 . This was the most frequent registration followed by no voluntary intake of drugs/alcohol up to $24 \mathrm{~h}$ prior to assault with $37.3 \%$ in 2019 and $17.5 \%$ in 2020 , however the difference was not statistically significant $(\mathrm{p}=0.059)$.

\section{Discussion}

Though the overall number of examinations of alleged victims of sexual assault did not change from 2019 to 2020, we found that the number of examinations per month was approximately stable in 2019 but increased through the months in 2020, assumingly due to the lockdown and the gradual reopening of the society in May and June.

In agreement with the existing literature, most assaults happened during the early morning (12 p.m. -6 a.m.) and during the weekend [16], though one study did not find a difference between the weekdays [13]. No significant difference between 2019 and 2020 was found regarding weekday and time of assault further emphasizing the risk of sexual assault to be greatest during this time of the day regardless of access to nightlife venues. Previous studies have found a relation to intake of alcohol and drugs [8] and since alcohol and drugs are still most commonly consumed during the late hours in the weekends, it is evidently still during this time of the week most assaults happen.

It has been shown in previous literature $[6,9,11,13,16]$ that most victims of sexual assault are young adults (age 15-25) which is consistent with our findings. Assumingly this age group is more prone to participate in the night life as well as having a prevalence for binge drinking behavior [2]. 125 cases out of 130 were female, in agreement with previous findings [16]. The number of male victims was too small to perform meaningful statistical analysis.

The most common assailant relation in both 2019 and 2020, was "known relation", consistent with previous literature $[2,11,14,16,23,24]$. Less sexual assaults by a stranger were registered in 2020 compared to 2019 , presumably due to the lockdown in 2020. Significantly more cases of sexual assault by a partner were registered in 2020 than 2019. This finding confirms a tendency that can also be seen in data regarding domestic violence during the lockdown [26, 27]. It is possible that an increase in domestic violence also leads to an increase in domestic sexual assault. Significantly, more assailants were registered as unknown in 2019 which is in line with the significantly greater number of individuals with complete amnesia in 2019 compared to 2020.

Consistent with previous findings, most sexual assaults happened in the assailant's house [7, 16]. This is in contrast to common beliefs that most sexual assaults happen in open space and by a stranger [2]. Interestingly the second most registered location of crime was open space in 2019, which is consistent with previous findings in the literature [7, 16], but not in 2020, where it was the victim's own home. One explanatory hypothesis could be that the lockdown of society complicated meeting in public spaces, leading to meetups in private homes instead, including that of the victim. This is further supported by the fact that no assaults were registered in bars/clubs in 2020, obviously due to the lockdown of these facilities. Published, non peer-reviewed data from the Copenhagen Centre for Sexual Assault [23] indicate that more victims report that contact with the perpetrator was established through online dating sites in 2020 than in 2019. Unfortunately, systematic registry of the means of contact between the victim and perpetrator is not part of our current accredited procedure for the forensic examination. We recommend future studies include this variable.

Contrary to our expectations, we did not find a decrease in possible DFSA-cases after the lockdown. Comparing the result to the fact that most assaults happened in the assailant's home and with the assailant being known relation, it could be hypothesized that the stable number of cases regarding possible DFSA is a result of an increased willingness to meet up for a drink in private homes instead of at public venues due to the lockdown. Alcohol was a highly prevalent factor in sexual assault cases in both 2019 and 2020. In general, voluntary intake of alcohol is very common and is often present in sexual assault cases which we also find to be the case in our study [13-16, 23].

Looking at the individual DFSA-associated factors, complete amnesia for the assault was significantly more common in 2019 compared to 2020, despite no significant difference in the number of cases where the victim suspected drink 
spiking. This is in line with research showing that the average intake of alcohol has decreased significantly in Europe during the Covid-19 lockdown [28]. It can be hypothesized that though we found no significant difference in proportions of cases with voluntary intake of alcohol between 2019 and 2020 , the amounts of alcohol consumed may have differed, so that larger amounts of alcohol would lead to more cases of amnesia as seen in 2019.

\section{Limitations}

It is important to note, that the number of examinations are non-equivalent to the actual number of sexual assaults since a lot of incidences are not examined, leaving a huge "dark figure" of assaults. The results of this study can be generalized only to cases with clinical forensic examinations of the victims which by all estimations comprises only a fraction of the actual number of sexual assaults in Danish society. It must be assumed that many cases of male as well as female victims are not reported due to stigma and taboo $[3,4,6,12]$. Furthermore, the study included data from help-seeking individuals whose victim characteristics might differ from those of less help-seeking individuals leading to reporting bias. Since it was a retrospective study design, it is possible that the victims did not provide data in exact accordance with the constructed database since categorization of the variables was defined after the clinical forensic examinations and victim testimonies. Given the many reports on partial or complete amnesia due to intoxication, but most likely also to psychological trauma, a degree of uncertainty in the reported data must be considered. Voluntary intake of alcohol was not automatically categorized as DFSA. The amount and rate of alcohol consumption was not registered and since alcohol is rapidly metabolized in the body, not all examinees appeared affected by ethanol at the examination, despite report of voluntary intake prior to the assault. In addition, the definition of intake of alcohol within $24 \mathrm{~h}$ prior to the assault, means that an intake of alcohol $20 \mathrm{~h}$ before the assault was registered but not necessarily related to the assault since a positive test relies on the above-mentioned amount and rate of alcohol consumption [17].

About half of the cases in the study were registered as possible DFSA, but it is important to note that some cases of DFSA might have been overlooked due to several factors. First, not all sexual assault victims are examined, due to the victim's feelings of guilt and shame, the victim's perception of the act as non-criminal or, though it is rare, rejection of the case by the police [18]. Secondly, a toxicological test is rarely performed because of a delay in report of the assault or because the police rarely choose to do the screening. Lastly, proving an opportunistic drug-facilitated sexual assault is usually very difficult. Few examinees appear affected by drugs or alcohol at the examination (less than $15 \%$ during both years) which might be a result of a delay in reporting as well as the amount and rate of consumption influencing both the appearance of the victim as well as the toxicological findings and suspicion of DFSA [14, 17]. This might be due to stigma and self-blaming by the victim as well as low acknowledgment of the assault from the victim [24].

\section{Conclusion}

In conclusion, this study indicates that the lockdown of the society did not change the overall number of clinical forensic examinations of sexual assault victims in Eastern Denmark. With regards to demographic and criminological characteristics of the assault, we found a significant decrease in sexual assaults by a stranger as well as a significant increase in sexual assault by a partner. Though the common belief that DFSA is a phenomenon most often seen in the night life, this study found no decrease in cases of possible DFSA despite the lockdown of the society.

Lastly, it is important to note that although this study uses the term "victim characteristics", the authors by no means intend to take away the responsibility of the perpetrator nor to place any blame with the victim.

\section{Key points}

1. This study compared the number of clinical exams of sexual assault victims in Eastern Denmark before and during the Covid-19 lockdown.

2. The Covid-19-based shutdown of Danish nightlife in 2020 had no effect on the total number of clinical exams.

3. Pre- and post-lockdown victim profiles were similar regarding assailant relation, location of crime and time of assault.

4. The proportion of possible drug-facilitated sexual assault was approximately $50 \%$ both years.

5. Total amnesia for the assault was reported by victims three times less frequently during the lockdown.

\section{References}

1. Borumandnia N, Khadembashi N, Tabatabaei M, Alavi MH. The prevalence rate of sexual violence worldwide: a trend analysis. BMC Public Health. 2020;20:1835.

2. Center for voldtægtsofre. Viden om voldtægt og seksuelle overgreb. Hentet fra: https://www.voldtaegt.dk/fa-viden/viden-omvoldtagt/. Accessed 12 Jul 2021. 
3. Pedersen A-JB, Kyvsgaard B, Balvig F. Udsathed for vold og andre former for kriminalitet Offerundersøgelserne 2005-2017. Justitsministeriet, Københavns universitet, Det kriminalpræventive råd, Rigspolitiet; 2018. Hentet fra: https://www.justitsministeriet.dk/sites/default/ files/media/Arbejdsomraader/Forskning/Forskningsrapporter/2018/ offerrapport_2005-2017ny.pdf. Accessed 28 Apr 2021.

4. Ingemann-Hansen O, Sabroe S, Brink O, Knudsen M, Charles AV. Characteristics of victims and assaults of sexual violence - Improving inquiries and prevention. J Forensic Leg Med. 2009;16:182-8.

5. Mose Wingender A. Center for Seksuelle Overgreb Årsstatistik 2020. Center for seksuelle overgreb; 2021 jan. Hentet fra: https:// www.rigshospitalet.dk/afdelinger-og-klinikker/julianemarie/ center-for-seksuelle-overgreb/for-fagfolk/Documents/aarsstatistikcso-2020.pdf.

6. Bang L. Who consults for rape? Sociodemographic characteristics of rape victims attending a medical rape trauma service at the Emergency Hospital in Oslo. Scand J Prim Health Care. 1993;11:8-14.

7. Hurley M, Parker H, Wells DL. The epidemiology of drug facilitated sexual assault. J Clin Forensic Med. 2006;13:181-5.

8. Du Mont J, Macdonald S, Rotbard N, Asllani E, Bainbridge D, Cohen MM. Factors associated with suspected drug-facilitated sexual assault. CMAJ. 2009;180:513-9.

9. Ingemann-Hansen O, Brink O, Sabroe S, Sørensen V, Charles AV. Legal aspects of sexual violence-does forensic evidence make a difference? Forensic Sci Int. 2008;180:98-104.

10. Crawford E, Wright MO, Birchmeier Z. Drug-facilitated sexual assault: college women's risk perception and behavioral choices. J Am Coll Health. 2008;57:261-72.

11. Haugen K, Slungård A, Schei B. Seksuelle overgrep mot kvinner - skademønster og relasjon mellom offer og overgriper. Tidsskrift for Den norske legeforening. 2005 [henvist 2. juli 2021]; Hentet fra: https://tidsskriftet.no/2005/12/aktuelt/seksuelle-overgrep-motkvinner-skademonster-og-relasjon-mellom-offer-og-overgriper. Accessed 2 Jul 2021.

12. Anderson LJ, Flynn A, Drummer O, Gerostamoulos D, Schumann JL. The role of voluntary and involuntary drug and alcohol consumption and premorbid mental health factors in drug-facilitated sexual assault. Forensic Sci Med Pathol. 2019;15:382-91.

13. Du Mont J, Macdonald S, Kosa D. An Examination of victim, assailant, and assault characteristics among cases classified as predatory drug-facilitated sexual assault. Womens Health Issues. 2016;26:393-400.

14. McBrierty D, Wilkinson A, Tormey W. A review of drug-facilitated sexual assault evidence: An Irish perspective. J Forensic Leg Med. 2013;20:189-97.

15. Lawyer S, Resnick H, Bakanic V, Burkett T, Kilpatrick D. Forcible, drug-facilitated, and incapacitated rape and sexual assault among undergraduate women. J Am Coll Hlth. 2010;58:453-60.
16. Tiemensma M, Davies B. Investigating drug-facilitated sexual assault at a dedicated forensic centre in Cape Town. South Africa Forensic Sci Int. 2018;288:115-22.

17. Birkler RID, Telving R, Ingemann-Hansen O, Charles AV, Johannsen M, Andreasen MF. Screening analysis for medicinal drugs and drugs of abuse in whole blood using ultra-performance liquid chromatography time-of-flight mass spectrometry (UPLCTOF-MS)-Toxicological findings in cases of alleged sexual assault. Forensic Sci Int. 2012;222:154-61.

18. Wingender AM, Engel Clasen L. Statusrapport 2017-2019 Center for Seksuelle Overgreb. Center for seksuelle overgreb; 2020 jun. Hentet fra: https://www.rigshospitalet.dk/afdelinger-og-klinikker/ julianemarie/center-for-seksuelle-overgreb/for-fagfolk/Documents/ Aarsrapporter/statusrapport-2017-2019.pdf. Accessed 28 Apr 2021.

19. Retsinformation. Lov om ændring af straffeloven. Hentet fra: https://www.retsinformation.dk/eli/lta/2020/2208. Accessed 4 May 2021.

20. Hall JA, Moore CBT. Drug facilitated sexual assault-a review. J Forensic Leg Med. 2008;15:291-7.

21. Cybulska B. Drug-facilitated rape. BMJ Sexual \& Reproductive Health. 2002;28:125.

22. Krebs CP, Lindquist CH, Warner TD, Fisher BS, Martin SL. College women's experiences with physically forced, alcohol- or other drug-enabled, and drug-facilitated sexual assault before and since entering college. J Am Coll Health. 2009;57:639-47.

23. Anderson LJ, Flynn A, Pilgrim JL. A global epidemiological perspective on the toxicology of drug-facilitated sexual assault: A systematic review. J Forensic Leg Med. 2017;47:46-54.

24. Littleton H, Grills-Taquechel A, Axsom D. Impaired and incapacitated rape victims: assault characteristics and post-assault experiences. Violence Vict. 2009;24:439-57.

25. Jakobsen LS, Jacobsen C, Lynnerup N, Steinmetz J, Banner J. Clinical forensic medicine in Eastern Denmark: Organisation and assessments. Med Sci Law. 2020;60:150-8.

26. Usher K, Bhullar N, Durkin J, Gyamfi N, Jackson D. Family violence and COVID-19: Increased vulnerability and reduced options for support. Int J Ment Health Nurs. 2020. https://doi.org/10.1111/inm.12735.

27. Van Gelder N, Peterman A, Potts A, O'Donnell M, Thompson K, Shah N, et al. COVID-19: Reducing the risk of infection might increase the risk of intimate partner violence. E Clinical Medicine. 2020;21:100348.

28. Kilian C, Rehm J, Allebeck P, Braddick F, Gual A, Barták M, et al. Alcohol consumption during the COVID-19 pandemic in Europe: a large-scale cross-sectional study in 21 countries. Addiction. [henvist 2. juli 2021];n/a. Hentet fra: https://doi.org/10.1111/ add.15530. Accessed 2 Jul 2021.

Publisher's Note Springer Nature remains neutral with regard to jurisdictional claims in published maps and institutional affiliations. 